labelled compounds, and to the chemist whenever information on the fate of a particular compound during a complex chemical reaction is required.

Mr. J. Wight (University of Strathclyde) read a paper on "The Examination of Food Volatiles by Gas Chromatography". He said that what we term 'flavour' is a combination of taste, smell or aroma, and the 'feel' of the food in the mouth. Of these the aroma is by far the most important and, since this depends on the presenceusually in minute amounts-of certain volatile compounds, the advantages of gas chromatography in aroma investigations become apparent. There are few gas-chromatographic techniques special to these investigations, and the main difficulties lie with the collection and concentration of the volatiles and with the identification of the com. ponents. Where large quantities of food have to be stripped of their volatiles, for example, by distillation, steam or nitrogen stripping, care must be taken to avoid loss or change; high-temperature treatment will almost certainly result in the production of artefacts.

Separation and identification are complicated by the large number of compononts present, the presence of chemically dissimilar classes of compounds and the wide range of retention times. Use must be made of techniques other than gas chromatography, and recently the mass spectrometer has proved to be a most powerful aid to identification.

There are many distinct applications of gas chromatography, for example, the general study of aroma volatiles, the production of aroma by cooking or processing, the investigation of flavour defects of stored foods and the quality control of materials such as essential oils.

It must be remembered that the results obtained by gas chromatography are essentially analytical and that these results have still to be interpreted in terms of aroma. In the absence of sufficient data on threshold values both of pure substances and of mixtures, it is important that the analytical work be supported by flavour panels. The aroma as sensed by the nose is, after all, the final criterion. Mr. Wight concluded his paper by showing chromatograms obtained from the volatiles of various common foodstuffs.

The final paper was read by Mr. J. Craig Higgins (National Coal Board) on "Developments in the Technique of Mine Air Analysis by Gas Chromatography". Mr. Higgins first of all pointed out that for the special problems involved in mine air analysis, no commercial gas chromatograph had been found suitable and a gas chromatograph had been designed and constructed at the laboratories of the National Coal Board.

He then went on to give a very full description of this gas chromatograph, which was a dual-column instrument but not in the usual sense of the meaning of dual column. Two different column packings were used, 'Molecular Sieve $5 X$ ' and silica gel, and detection was by thermal conductivity cells. By means of a special valve system, samples of the gas to be analysed were put on to both columns simultaneously and flow rates were adjusted so that the components from one column were recorded before the components started to emerge from the second column. In using this system a complete analysis of the mine gas eould be recorded on the one chromatogram.

Mr. Higgins ended by showing how these chromatographs were used in the National Coal Board's mobile laboratories, and he pointed out that wherever possible duplication of equipment was essential to obviate any breakdown or failure of components in these mobile laboratories.

The symposium concluded with an address by Mr. A. C. Low of the Ministry of Technology. G. R. JAMresson

\title{
CNIDARIA AND THEIR EVOLUTION
}

$\mathrm{T}$ HE Zoological Society of London organized a symposium during March 3-4, at which evolution in the Cnidaria as well as many diverse aspects of this plastic group were reviewed and discussed.

Opening the symposium, Prof. C. F. A. Pantin (Cambridge) gave a stimulating address on "Homology, Analogy and Chemical Identity". To the first two, he added "chemical identity", that is, resemblances which can be traced to the absolute similarity of each set of isotopes in the Periodic Table and of the molecules built from them. He indicated that chemical identity can give rise to packing phenomena, as in crystals, creating welldefined morphological features, far above the atomic level, which are, or partially only, the result of adaptive selection. The independent appearance of particular classes of molecule such as are found in pigments and other 'chemical building stones' arises from chemical identity. Much caution should therefore be adopted in using features of this kind as evidence of evolutionary relationship.

Prof. Pantin indicated that analogy arises because natural selection operates by setting the organism engineering specifications for each part that must be realized for survival. $\mathrm{He}$ regarded the longitudinal musculature of cnidarian polyps as an example of a weak specification allowing many solutions. On the other hand, rigid and detailed specifications like those responsible for close similarities in complex eyes are not evident in the Cnidaria.

Homologies of parts account for the most characteristic resemblances between animals, these homologies depending on a plan or archetype to which the structure of all species in the class may be referred. This archetype (which is not an ancestor) and its homologies he considered as a network of tissue relationships. Further, he thought the system as a whole met an engineering requirement and that natural selection acted strongly against any serious departure from the network of tissue relationships. However, this network could be distorted to meet the needs of adaptive radiation, and as examples he quoted the different mesenteric patterns of the Anthozoa.

Dr. L. F. R. Picken and Dr. R. J. Skaer (Cambridge) gave a lucid review of researches on nematocysts and dealt comprehensively with the subject. Among other interesting items, the authors discussed a new aspect of nematocyst chemistry - phosphatases, 5-nucleotidase and cholinesterase. Several amino-acid analyses of nematocysts isolated in bulk are now available and something is known of certain other chemical components.

There was also a very intoresting demonstration, from electron microscope investigations, that the wall of the undischarged thread in isorhizas of Corynactis viridis is pleated to form a triple screw and that the undischarged capsules have a 'notional' osmotic pressure up to approximately 140 atmospheres.

The authors believe that cnidoblasts may still be regarded as independent effectors although the excitationthreshold of the enidocil-cnidoblast unit may be under nervous control in some instances, depending on the physiological condition of the animal. It olso emerged that taxonomic investigations on the different kinds of nematocysts, based on the light microscope, are not enough and that further electron-microscope examinations are essential.

Dr. David Chapman (Halifax, Nova Scotia) developed some interesting ideas regarding the origins of the Seyphozoa from an examination of the anatomy of the scyphistoma of Aurelia. He was inclined to regard the fossil conulariids as ancestral to this group, basing his conclusions on certain puzzling features in the anatomy of the scyphistoma which could be explained by adopting 
this evolutionary concept. A new notion that mesoderm is found in polyps in the form of a surface epithelium was linked with the formation of podocysts and like structures. Dr. Chapman concluded from the behavioural investigation that the polypoid preceded the medusoid stage in the evolution of the Scyphozoa and further suggested that the seyphopolyp was the simplest cnidarian polyp. The development of the strobila was regarded as an aeration device for devcloping gametes. Dr. Chapman concluded his paper with a discussion of the modifications of the scyphistoma in the class, in which he regarded the rhizostome scyphistoma as a very simple cnidarian polyp possessing a complex medusa. This would, in offect, be an example of mosaic ovolution although Dr. Chapman did not actually call it so.

From a review of the five orders of Scyphozoa, Dr. Hjalmar Thiel (Hamburg) concluded that the scyphozoan stem form was a tetraradiate polyp with four tentacles, four peristomial pits and four septa, which ancestrally also possessed four or eight gonads on the septa. He derived the metagenotic development of the medusa from the transverse fission of the scyphistoma in which the products of the fission were originally daughter polyps evolving by way of a planktonic life into medusae. The Stauromedusac, a group that combincs polypoid and medusoid characteristies, he regarded as having originated through the fusion of the two generations (scyphopolyp and medusa), or in other words an arrested metagenetic development.

The interstitial fauna of sandy beaches and sub-littoral sand contains some very interesting forms and among them some minute Hydrozoa. Since Remane described two actinula-like forms which he called Halammohydra in 1927, a further two and a new genus, Otohydra, have been investigated at Roseoff by Dr. B. Swedmark and Prof. G. Teissier (Kristineberg and Roscoff). In their "contribution to this symposium they rcviewed these strange forms (combining the characteristics of polyp and medusa, as well as possessing larval features). These they have placed in a new order, the Actinulida. In their comprehensive survey of these aberrant forms, Dr. Swcdmark and Prof. Teissier consider that the $\Lambda$ ctinulida have arisen from an ancestral actinula which colonized the interstitial environment very early on and there acquired statocysts - a type of organ very common in many different organisms in this environment. In other words, vague suggestions made over the years that the Actinulida are reduccd Narcomedusae that have adopted an interstitial habitat are rejected, but, in the discussion that followed, Dr. B. Werner indicated his adherence to the older concept. This paper was followed by a film of Halammohydra made at Roscoff.

The evolution of the Actiniaria was discussod in a controversial and stimulating paper by Prof. Cadet Hand (California), who was led from an investigation of the puzzling pattern of development of mesenteries, first as couples and later as pairs, to consider the origins of sea anemones. He pointed out that coupling has an adaptive value in preserving symmetry round the mouth axis but that the pairing of mesenteries does not have this significance. However, in contrast to the situation in the madrepores, the pairing of mesenteries was demonstrated to be an adaptive and functional character. Accordingly, Dr. Hand suggested that the Actiniaria have been derived from corals and, furthermore, that the so-called primitive ancmones (Athenaria) may be better considered as secondarily dorived forms-thus revorsing present ideas. From this new hypothesis the thenarian anernones would be the most generalizod and most closely related to corals, and from these a course of evolution to the acontiate anemones and to the athenarian forms was traced.

Prof. Garth Chapman (London) reviewed the structure, function and what is known of tho origin of the mesogloea. In many species the mesogloea is of a fibrous nature and, from its amino-acid composition and
X-ray diffraction pattern, may be called a collagen. It was pointed out that the scyphomedusan mesogloea would probably bo ropresented as a simple polymeric gel, whereas the mechanieal proporties of the actinians may be best represented as a parallel cross-linked and a noncross-linked polymcric system. It emerged that the functions of the mesogloea are diverse, boing neither clearcut nor uniform, but include acting as antagonist to muscle, flotation and as a possiblo nutritional reservo.

Dr. Maxwell Braverman (Pittsburgh) reviewed his work with Dr. R. S. Schrandt on the development of the athccate hydroid Podocoryne carnea by culture from single individuals on microscope slides and gave a fascinating account of an attempt (in collaboration with Dr. Robert G. Schrandt, of Los Alamos Scientific Laboratory) to simulate this devclopment on an electronic computer. He demonstrated how the computer generates a relatively complex pattern as a mathematical model of the growing system by the itoration of a set of simple rules of growth. This growth, which consists of a connectod network of points in a two-dimensional net, can be followed generation by generation and selected parameters of the generatod pattern compared with those of real colonies. Dr. Braverman also suggested that the ability of simple recursive rules to gencrate complex patterns may mean that gonetic instructions of developing systems may be partly of a similar nature. From the discussion that followed it also emerged that the production of reproductive hydranths is stimulated by an increase in the carbon dioxide in the stolons that give rise to them.

The various theories concerning the origin and evolution of the Hydrozos were discussed by Dr. W. J. Rees (London), who attempted to provide an explanation of the origin of metagenesis (the alternation of a fixed benthic hydroid phase with a free-swimming medusa phase). Many early authorities were disposed to regard the tetraradiate polyp as a busic cnidarian, but this is too specialized an organism. It was suggested that the protocoelenterate was a gastrula and that the ancestral cnidarian was a fertile actinula. The actinula possesses all the basic features which through radiation could give rise to all three classes. In this way, the adoption of a pelagic habit probably led to the evolution of Trachymedusae with a direct life-cycle (egg-planulae-adult medusa) and to the Narcomedusao also with a direct life cycle. In the latter, however, some forms such as Pegantha exhibit the beginnings of a metagenosis, while the Hydromedusae living to-day possess a well-developed metagenesis, even in the most primitive family, the Moorisiidae. In the hydroids and modusae the trend is towards the elaboration of the hydroid and the gradual suppression of the medusa. This trend would not appear to be the other way round, as Hadži would have us believe in his Turbollaria theory of the origin of the Cnidaria.

The mushroom corals (Fungiidae), both recent and fossil, were reviewed by Prof. J. W. Wells (New York), who discussed their present status from the stratigraphic, biogeographic and systematic aspects. It was shown that they well illustrate an evolutionary trend (which is common to most living and extinct zoantharian corals), a tendency towards colonial or polycentric forms from the basic monostomatous condition found in Fungia. Prof. Wells, who also provided a key and synopsis of genera (including several new ones), considered that this ovolutionary trend in fungiids is in full spate at the present timo, whereas in most scleractinian groups it has already reached its full development. Cycloseris appeared in the early Tertiary, and by Miocene times the central form Fungia had evolved from it. Radiation in Fungia gavo rise to several sub-gonera which by the late Miocene had given rise to simple polystomatous types, and Prof. Wells thought it probable that by the Pleistocene times all eight of the so-called colonial genera had probably 
developed, although three of these are so far known only from the Recent.

In his account of pathways of excitation in Ctenophora, Dr. G. A. Horridge (St. Andrews) analysed the conducting systems principally in Beroë and Cestum, referring also to other species he had investigated. He recognized four conducting systems and, without going into details here, concluded that separate conducting systems arise and multiply in primitive nervous systems independently and without the establishment of functional contacts with the neurones of other pathways. This he regarded as a necessary formula for the development of a central nervous system.

M. Yves Bouligand gave a comprehensive review of all known ectoparasitic and endoparasitic copepods associated with Anthozoa. Most of these are ectoparasitic, belonging to the families Asterocheridae and Lichomolgidae and to the Xarifidae. This third family has numerous species associated with Madreporaria.

All the endoparasitic copepods belong to the family Lamippida - a family in which the sexes exhibit a marked degree of dimorphism. There is a considerable amount of deformity, but the characteristics of the integument and of the musculature enable the metameric plan to be worked out. The ultrastructures of the cuticle seem to show that this is involved in nutritional functions in several species. Various aspects of host-parasite relations were also discussed.

A contribution from Dr. J. H. Barnes (Cairns, North Queensland) dealt with three species of venomous Cubomedusae; these were: a small and as yet unidentified carybdeid (the cause of the Irukandji sting), Chiropsalmus quadrigatus Haeckel and Chironex fleckeri Southcott; the last of these being identified as the only lethal form and the probable cause of at least fifty deaths in North Australian waters. Chironex fleckeri, probably the most venomous marine invertebrate known, may kill bathers, in cases of massive envenomation, in 3 minutes or less. Dr. Barnes's lucid and comprehensive paper may be regarded as an interim report on present progress in identifying the organisms, on treatment and on investigations in train.

Dr. Elaine Robson (Cambridge) reviewed the evolution of the swimming habit in tho Actiniaria-a process which she believes originated independently in the Goniactinidae, the Boloceroididae and the Actinostolidae. In all, the swimming reflects the temporary excitation of pacemaker elements in the nervous system, and its evolution in at least three separate groups may partly be attributed to the fundamental properties of the coelenterate neuromuscular system. Dr. Robson suggested that pre-adaptive features such as the presence of well-developed ectodermal neuromuscular elements and weak basilar musculature, in forms that use the tentacles, and of well-developed parieto-basilar muscles in those that bend the column, may be significant. It is further suggested that comparatively minor quantitative changes in neuromuscular and receptor properties may have far-reaching effects in actiniarian behaviour.

Prof. Demorest Davenport (California) reviewed recent progress in the study of cnidarian symbioses, giving a lively account of work on the behaviour, inter alia, of the sea anemone Calliactis in relation to its normal substratum (shells occupied by hermit crabs). In particular, he discussed the unique sensory discriminatory power of the tentacles of the anemone to recognize the periostracum of the shell. This work (with which Prof. D. M. Ross is also associated) was illustrated towards the end of the meeting by some remarkably revealing colour films of Calliactis behaviour and also of the swimming behaviour of Stomphia exhibited by Prof. Ross.

The phylogenetic and evolutionary value of skeletal formations in athecate hydroids was discussed by Dr. W. Vervoort (Leiden), who was concerned with the family Solanderiidae. It was demonstrated that the idea of a mesogloeal skeleton of the Solanderiidae was no longer tenable and that as in other capitate hydroids the skeleton was ectodermal in origin. Dr. Vervoort also demonstrated that the genus Rosalinda should be placed in this family, being able to accept neither Picard's placing of this genus in the Zancleidae nor his concept of "Pteronematoidea" as a super-family. It was also his opinion that too much stress should not be laid on the value of nematocysts in classification without adequate support from morphological evidence.

Growth in the hydroid Tubularia crocea L. Agassiz was discussed by Dr. G. O. Mackie (Edmonton, Alberta). This species was cultured for ten weeks at Villefranche in clean sea-water at $14^{\circ} \mathrm{C}$; a diet of Artemia was found satisfactory. Continuous growth was recorded in both stolons and hydrocauli along with the production of many new hydranths. Dr. Mackie recorded the patterns of growth for an established colony and for settled actinulae. It appears that hydranths retain full regenerative ability, and although shedding of hydranths was seen, most of them were never shed during the period of investigation. Contrary to some prevailing assumptions, there is no evidence that hydranths become senescent, requiring to be replaced pericdically. Hydrocauline growth does not depend on such replacements and it was suggested that hydranth shedding is associated with poor water conditions, and that, given favourable ones, hydranths probably live indefinitely. Dr. Mackie's results thus question earlier conclusions that periodic hydranth shedding is a normal feature of the life of Tubularia.

M. Jacques Theodor (Banyuls) exhibited a remarkable series of clear underwater photographs of cnidaria which he had photographed in situ in the Mediterranean and in the Pacific. There was also a demonstration of living Stephanoscyphus polyps by Dr. B. Werner (Heligoland), who had recently returned from a cruise in the German research vessel Meteor.
W. J. REES

\title{
MECHANISM OF POPULATION INVERSION AT 6I49 A IN THE MERCURY ION LASER
}

\author{
By DR. D. J. DYSON \\ Valve Department, Ferranti Ltd., Edinburgh
}

$\mathrm{F}^{\mathrm{o}}$ OLLOWING the first report of the mercury ion laser by Bell ${ }^{1}$, several further reports have been published ${ }^{2-4}$. Apart from some tentative suggestions by Bell et al. ${ }^{2}$ no definite conclusions as to the mechanisms of selective population of the upper laser levels have been put forward. This article describes some results of the observation of the time-variation of the spontaneous emission from the helium-mercury discharge which appear to clarify the mechanism responsible for excitation of the $6149 \AA$ laser transition in this system.

Fig. 1 shows the intensity, as a function of time, of some spontaneous emission lines from a helium-mercury vapour mixture, following the discharge through it of a condenser of a few hundred picofarads charged to $5-10 \mathrm{kV}$. These excitation conditions are favourable for laser action at $6149 \AA$. The $5460 \AA$ line showed a time variation 